\title{
Bacteria and poisonous plants were the primary causative hazards of foodborne disease outbreak: a seven-year survey from Guangxi, South China
}

Yongqiang $\mathrm{Li}^{1,2+}$, Yaling Huang ${ }^{3,4,5+}$, Jijun Yang ${ }^{2}$, Zhanhua Liư ${ }^{7}$ Yanning $\mathrm{Li}^{8}$, Xueting $\mathrm{Yao}^{7}, \mathrm{Bo} \mathrm{Wei}^{2}$,

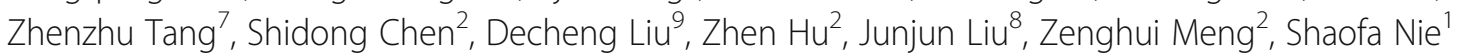
and Xiaobo Yang ${ }^{4,5,6^{*}}$

\begin{abstract}
Background: Foodborne diseases are a worldwide public health problem. However, data regarding epidemiological characteristics are still lacking in China. We aimed to analyze the characteristics of foodborne diseases outbreak from 2010 to 2016 in Guangxi, South China.

Methods: A foodborne disease outbreak is the occurrence of two or more cases of a similar foodborne disease resulting from the ingestion of a common food. All data are obtained from reports in the Public Health Emergency Report and Management Information System of the China Information System for Disease Control and Prevention, and also from special investigation reports from Guangxi province.
\end{abstract}

Results: A total of 138 foodborne diseases outbreak occurred in Guangxi in the past 7 years, leading to 3348 cases and 46 deaths. Foodborne disease outbreaks mainly occurred in the second and fourth quarters, and schools and private homes were the most common sites. Ingesting toxic food by mistake, improper cooking and cross contamination were the main routes of poisoning which caused 2169 (64.78\%) cases and 37 (80.43\%) deaths. Bacteria (62 outbreaks, 44.93\%) and poisonous plants (46 outbreaks, 33.33\%) were the main etiologies of foodborne diseases in our study. In particular, poisonous plants were the main cause of deaths involved in the foodborne disease outbreaks (26 outbreaks, 56.52\%).

Conclusions: Bacteria and poisonous plants were the primary causative hazard of foodborne diseases. Some specific measures are needed for ongoing prevention and control against the occurrence of foodborne diseases.

Keywords: Foodborne diseases, Foodborne disease outbreaks, Epidemiology

\section{Background}

Foodborne diseases have been an issue for all societies and are a continuing public health problem. Annually, onethird of people worldwide are infected by foodborne pathogens [1]. The Foodborne Disease Burden Epidemiology Reference Group (FERG), established by the World Health

\footnotetext{
* Correspondence: yxbo21021@163.com

${ }^{\dagger}$ Equal contributors

${ }^{4}$ Center for Genomic and Personalized Medicine, Guangxi Medical University, Nanning, Guangxi, China

${ }^{5}$ Guangxi Collaborative Innovation Center for Genomic and Personalized

Medicine, Nanning, Guangxi, China

Full list of author information is available at the end of the article
}

Organization (WHO) in 2007, estimated that 31 foodborne hazards caused 600 million foodborne illnesses and 420,000 deaths in 2010 [2]. In addition, the global burden of foodborne disease by these 31 hazards was 33 million disabilityadjusted life years (DALYs) in 2010. Therefore, more attention should be focused on foodborne disease.

In developing countries, such as China, food safety remains a social health problem, playing a crucial role in public health [3], and it is directly related to social stability. From 2001 to 2010, 5021 outbreaks of foodborne disease were reported in China, causing 140,101 illnesses and 1427 deaths [4]. From 2004 to 2013, the mortality 
rate of foodborne diseases was $1.9 \%$ in China [5]. Major sources of foodborne diseases in China include pathogenic microorganisms, toxic insects/food products and plants entering the food supply, and chemical contamination [6]. A total of 371 outbreaks related to bacterial foodborne diseases were reported in China between 2008 and 2010, and 20,062 cases and 41 deaths were involved [7]. Since 2000, a total number of 52 cases of mushroom poisoning due to Amanita exitialis have been reported, causing 20 deadths [8].

Foodborne diseases and diseases potentially transmitted by food are investigated by the China Food and Drug Administration (CFDA) in China. The CFDA conducts surveillance in the Public Health Emergency Report and Management Information System of the China Information System for Disease Control and Prevention. The CFDA has monitored illness trends, detected outbreaks, provided information about preventative measures, evaluated the efficacy of intervention efforts and carried out work based on the Food Safety Law since 2009.

Although the surveillance system for foodborne diseases and the law on food safety have been effective in China, foodborne diseases remain a severe public health problem, and few studies or data analyses have focused on it. In this paper, we investigated the prevalence and epidemiological characteristics of foodborne disease outbreaks from 2010 to 2016 in Guangxi, and provided evidence for the ongoing prevention and control against foodborne diseases.

\section{Methods}

\section{Definitions}

Foodborne disease is defined as any disease of an infectious or toxic nature caused by consumption of food [9], with clinical symptoms, such as nausea, vomiting, abdominal pain, diarrhea, other gastrointestinal symptoms or nerve symptoms of poisoning. Food poisoning cases are reported on the basis of assessment by physicians at the hospital and confirmed by epidemiologists from local Centers for Disease Control (CDC). A foodborne disease outbreak is the occurrence of two or more cases of similar foodborne disease resulting from the ingestion of a common food. In this study, we analyzed only outbreaks that were caused by diseases of toxic nature (vs. infectious).

We divided a year into four quarters: the first quarter (January, February, March), the second quarter (April, May, June), the third quarter (July, August, September) and the fourth quarter (October, November, December).

\section{Data collection}

The official statistics regarding foodborne disease outbreaks reported between 2010 and 2016 in Guangxi were downloaded from the information reported in the
Public Health Emergency Report and Management Information System of the China Information System for Disease Control and Prevention, and were summarized from foodborne disease special investigation reports around Guangxi. A single outbreak was reported on a food hygiene incident report card. The card contains the number of cases and deaths, onset date, outbreak areas and sites, implicated foods, contributing factors and causative hazards. Implicated foods were categorized as grains, meat and poultry, seafood, eggs, dairy products, cakes and bakery products, vegetables, toxic insects/food products, poisonous plants and others, which were not confirmed. Contributing factors include material contamination and deterioration, equipment contamination, handling contamination, improper cooking, cross contamination, long preparation time, ingesting poisonous food by mistake and deliberate poisoning. Causative hazards, such as bacteria, poisonous plants, chemical agents and toxic insects/food products, were confirmed by laboratory tests and epidemiological investigation. Factors which failed to be detected by existing laboratory conditions but confirmed by epidemiological investigation were classified as "unconfirmed". The outbreak areas were categorized as village, town and city. The outbreak sites were categorized as canteens, private homes, schools, restaurants and delicatessens. All the laboratory test methods were performed in accordance with national methods of food hygienic analysis.

\section{Statistical analysis}

All analyses were performed using SPSS statistical program, version 16.0. A chi-square test was used to compare differences in death among quarters and areas, and causative hazard. The Bonferroni test was used for pairwise comparison of death. A nominal two-sided $P$ value less than 0.05 was considered to indicate statistical significance. A twosided $P^{\prime}$ value less than $\frac{0.05}{C_{k}^{2}}$ ( $\mathrm{k}$ represents the number of groups) was considered to indicate statistical significance in the Bonferroni test. All tables and figures were devised using Microsoft Excel software, version 2007 and GraphPad Prism, version 5.01, respectively.

\section{Results}

\section{General characteristics}

From 2010 to 2016, 138 foodborne disease outbreaks occurred, with a mean of 19.7 (ranging from 11 to 29) foodborne disease outbreaks being reported annually (Table 1). A total of 3348 cases and 46 deaths were involved in foodborne disease outbreak during those 7 years, with 24.26 cases per outbreak. The morbidity of foodborne disease outbreak ranged from 0.63 to 1.59 
Table 1 Number of outbreaks, cases and deaths by year, Guangxi, South China, 2010-2016

\begin{tabular}{|c|c|c|c|c|c|}
\hline Year & No.(\%) of outbreaks & No.(\%) of cases & No.(\%) of deaths & Morbidity $^{a}(1 / 100000)$ & Case fatality rate $(\%$ \\
\hline 2010 & $21(15.22)$ & $444(13.26)$ & $11(23.91)$ & 0.96 & 2.48 \\
\hline 2011 & $29(21.01)$ & $738(22.04)$ & $13(28.26)$ & 1.59 & 1.76 \\
\hline 2012 & $16(11.59)$ & $343(10.24)$ & $6(13.04)$ & 0.73 & 1.75 \\
\hline 2013 & $11(7.97)$ & $296(8.84)$ & $3(6.52)$ & 0.63 & 1.01 \\
\hline 2014 & $21(15.22)$ & $625(18.67)$ & $2(4.35)$ & 1.31 & 0.32 \\
\hline 2015 & $21(15.22)$ & $409(12.22)$ & $8(17.39)$ & 0.85 & 1.96 \\
\hline 2016 & 19 (13.77) & $493(14.73)$ & $3(6.52)$ & 1.03 & 0.61 \\
\hline total & 138 & 3348 & 46 & 1.02 & 1.37 \\
\hline
\end{tabular}

${ }^{\mathrm{a}}$ The morbidity were calculated basing on the Guangxi population reported in Guangxi Statistical Year book

cases per 100,000 people, and the case fatality rates ranged from 0.32 to $2.48 \%$.

\section{Time distribution}

The lowest number of outbreaks (28 of 138, 20.29\%) and cases $(704$ of $3348,21.03 \%$ ) occurred in the first quarter compared to the other three quarters (Table 2). The case fatality rate in the third quarter $(0.42 \%)$ was the lowest, while it was the highest in the fourth quarter $(1.87 \%)$. The outbreaks mainly occurred in January, April, November, October, May and July, and in February the number of cases was the lowest during months investigated. In addition, the case fatality was the highest in May (Additional file 1). A significant difference was found for death between the second and third quarters, and between the third and fourth quarters $(p=0.018)$.

\section{Distribution of areas and sites}

The outbreaks were likely to occur in villages and towns. As shown in Table 2, the proportion of outbreaks and cases in villages and towns were higher than that in cities. As for the occurring sites, the places of outbreaks were mainly located in schools (59 of 138, 42.75\%) and private homes (45 of 138, 32.61\%). The cases tended to be concentrated in schools (1600 of 3348, 47.79\%), whereas the deaths mainly occurred in private homes (36 of $46,78.26 \%$ ) (Table 3 ).

\section{Categories of poisoning food and transmission routes}

Up to ten kinds of food were found to be related to foodborne disease outbreaks. The top three were poisonous plants $(46,33.33 \%)$, mixed food $(39,28.26 \%)$ as well as meat and poultry $(15,10.87 \%)$. In particular,

Table 2 Number of outbreaks, cases and deaths of quarters, areas and causative hazard, Guangxi, South China, 2010-2016

\begin{tabular}{|c|c|c|c|c|c|}
\hline & No.(\%) of outbreaks & No.(\%) of cases & No.(\%) of deaths & Case fatality rate (\%) & $\overline{p \text { value }}{ }^{a}$ \\
\hline Quarters ${ }^{b}$ & & & & & 0.008 \\
\hline First & $28(20.29)$ & $704(21.03)$ & $9(19.57)$ & 1.28 & \\
\hline Second & $39(28.26)$ & $963(28.76)$ & $19(41.30)$ & 1.97 & \\
\hline Third & $31(22.46)$ & $931(27.81)$ & $4(8.70)$ & 0.43 & \\
\hline Fourth & $40(28.99)$ & $750(22.40)$ & $14(30.43)$ & 1.87 & \\
\hline Areas $^{c}$ & & & & & 0.001 \\
\hline Village & $50(36.23)$ & $1202(35.90)$ & $20(43.48)$ & 1.66 & \\
\hline Town & $50(36.23)$ & $1158(34.59)$ & $23(50.00)$ & 1.99 & \\
\hline City & $38(27.54)$ & $988(29.51)$ & $2(6.52)$ & 0.30 & \\
\hline Causative hazard ${ }^{d}$ & & & & & $<0.001$ \\
\hline Bacteria & $62(44.93)$ & $2123(63.41)$ & $6(13.04)$ & 0.28 & \\
\hline Chemical agents & $9(6.52)$ & $131(3.91)$ & $8(17.39)$ & 6.11 & \\
\hline Toxic insects/food products & $3(2.17)$ & $15(0.45)$ & $3(6.52)$ & 20.00 & \\
\hline Poisonous plants & $46(33.33)$ & $711(21.24)$ & $26(56.52)$ & 3.66 & \\
\hline Factors unconfirmed & $18(13.04)$ & 368 (10.99) & $3(6.52)$ & 0.82 & \\
\hline Total & 138 & 3348 & 46 & 1.02 & \\
\hline
\end{tabular}

${ }^{\mathrm{a}}$ Differences in death among quarters, areas, and causative hazard were compared by Chi-Square test. ${ }^{\mathrm{b}}$ Differences in death were significant in the comparison of the second and the third quarter, and the comparison the third and the fourth quarter $(p=0.018)$. ${ }^{c}$ Differences in death were significant in all areas pairwise comparison $(p=0.017)$ except comparison of village and town $(p=.0558){ }^{d}$ Differences in death were significant in all causative hazard pairwise comparison ( $p=$ 0.018 ) except comparison of chemical agents and toxic insects/food products $(p=0.053)$, and chemical agents and poisonous plants $(p=0.191)$ 
Table 3 Number of outbreaks, cases and deaths by site, Guangxi, South China, 2010-2016

\begin{tabular}{lllll}
\hline Site & No.(\%) of outbreaks $(n=138)$ & No.(\%) of cases $(n=3348)$ & No.(\%) of deaths $(n=46)$ & Case fatality rate $(\%)$ \\
\hline Canteens & $7(5.07)$ & $106(3.17)$ & $0(0.00)$ & 0.00 \\
Private homes & $45(32.61)$ & $814(24.31)$ & $36(78.26)$ & 4.42 \\
Schools & $59(42.75)$ & $1600(47.79)$ & $0(0.00)$ & 0.00 \\
Restaurants & $10(7.25)$ & $407(12.16)$ & $0(0.00)$ & 0.00 \\
Delicatessens & $9(6.52)$ & $299(8.93)$ & $0(0.00)$ & 0.00 \\
Others $^{\text {a }}$ & $8(5.80)$ & $122(3.64)$ & $10(21.74)$ & 8.20 \\
\hline
\end{tabular}

${ }^{\mathrm{a} O t h e r}$ sites include construction sites and field

poisonous plants were the main cause of death involved in the foodborne disease outbreaks $(26,56.52 \%)$ (Table 4). The transmission routes of foodborne disease outbreaks were diverse. We found that ingesting poisonous food by mistake, improper cooking methods and cross contamination were the main transmission routes, causing 2169 $(64.78 \%)$ infection cases and $37(80.43 \%)$ deaths. Ingesting poisonous food by mistake was the main cause of death (35 of 46, 76.09\%), and deliberate poisoning caused a high case fatality rate $(50.00 \%)$ (Table 5$)$.

\section{Causative hazard}

The causative hazards were classified into bacteria, poisonous plants, chemical agents and toxic insects/food products. Bacteria (62 of 138, 44.93\%) and poisonous plants $(46,33.33 \%)$ were the first and second factors for foodborne disease outbreaks, respectively (Table 2). In addition, the main species of bacteria contributing to foodborne disease outbreaks were Salmonella, Vibrio parahaemolyticus and Staphylococcus aureus (Fig. 1). Tung oil fruit or tung oil, Gelsemium elegans and toxic mushroom were the primary sources of poisoning from poisonous plants (Fig. 2). Contaminations by Burkholderia gladioli (6 of 46, 13.04\%), toxic mushroom (5 of $46,10.87 \%$ ) and Gelsemium elegans (17 of 46, 36.96\%) were the main factors for deaths (Table 6). Notably, there were 30 outbreaks in which the causative hazard could not be found, involving 719 cases and 9 deaths. Significant differences were found in the deaths of the five causative hazards $(p<0.001)$, and deaths caused by toxic insects/food products was higher than those caused by bacteria and poisonous plants.

\section{Discussion}

Suspicious food, contributing outbreak factors and specific causative hazard are the most crucial elements of foodborne disease outbreaks. If the linkages among them were found and appropriate measures were taken, the number of foodborne disease outbreaks could be controlled. In the present study, we investigated 138 foodborne disease outbreaks from 2010 to 2016 in Guangxi, South China; our data showed that the rates of foodborne disease outbreaks that occurred in the second and fourth quarters were higher than those in the first and third quarters. The foodborne disease outbreaks were likely to occur in schools. The main contributing factors of foodborne disease outbreaks included ingesting poisonous food by mistake, improper cooking and cross contamination, and the main causative hazard of

Table 4 Number of outbreaks, cases and deaths by different kinds of food, Guangxi, South China, 2010-2016

\begin{tabular}{lllll}
\hline Food & No.(\%) of outbreaks $(n=138)$ & No.(\%) of cases $(n=3348)$ & No.(\%) of deaths $(n=46)$ & Case fatality rate $(\%)$ \\
\hline Grains & $8(5.80)$ & $164(4.90)$ & $6(13.04)$ & 3.66 \\
Meat and poultry & $15(10.87)$ & $513(15.32)$ & $0(0.00)$ & 0.00 \\
Seafood & $5(3.62)$ & $141(4.21)$ & $0(0.00)$ & 0.00 \\
Eggs & $2(1.45)$ & $54(1.61)$ & $0(0.00)$ & 0.00 \\
Dairy products & $1(0.72)$ & $15(0.45)$ & $0(0.00)$ & 0.00 \\
Cakes and bakery products & $4(2.90)$ & $94(2.81)$ & $0(0.00)$ & 0.00 \\
Vegetables & $2(1.45)$ & $51(1.52)$ & $0(0.00)$ & 0.00 \\
Toxic insects/food products & $3(2.17)$ & $15(0.45)$ & $3(6.52)$ & 20.00 \\
Poisonous plants & $46(33.33)$ & $711(21.24)$ & $26(56.52)$ & 3.66 \\
Mixed food ${ }^{a}$ & $39(28.26)$ & $1238(36.98)$ & $4(8.70)$ & $7(15.22)$ \\
Others $^{\text {b }}$ & $13(9.42)$ & $352(10.51)$ & 0.32
\end{tabular}

${ }^{a}$ Mixed Food was identified as at least two kinds of food involved in a food poisoning incident

${ }^{b}$ Other kind of food include frog and the food we cannot confirm 
Table 5 Number of outbreaks, cases and deaths by different ways of poisoning, Guangxi, South China, 2010-2016

\begin{tabular}{|c|c|c|c|c|}
\hline Contributing factors & No.(\%) of outbreaks $(n=98)$ & No.(\%) of cases $(n=2446)$ & No.(\%) of deaths $(n=35)$ & Case fatality rate (\%) \\
\hline Material contamination and deterioration & $14(10.14)$ & $317(9.47)$ & $6(13.04)$ & 1.89 \\
\hline Equipment contamination & $2(1.45)$ & $99(2.96)$ & $0(0.00)$ & 0.00 \\
\hline Handlers contaminating & $2(1.45)$ & $118(3.52)$ & $0(0.00)$ & 0.00 \\
\hline Improper cooking & $27(19.57)$ & $849(25.36)$ & $2(4.35)$ & 0.24 \\
\hline Cross contamination & $20(14.49)$ & $747(22.31)$ & $0(0.00)$ & 0.00 \\
\hline Long preparation time & $9(6.52)$ & $232(6.93)$ & $1(2.17)$ & 0.43 \\
\hline Ingesting poisonous food by mistake & $45(32.61)$ & $573(17.11)$ & $35(76.09)$ & 6.11 \\
\hline Deliberate poisoning & $1(0.72)$ & $2(0.06)$ & $1(2.17)$ & 50.00 \\
\hline Others $^{a}$ & $18(13.04)$ & $411(13.04)$ & $1(2.17)$ & 0.24 \\
\hline
\end{tabular}

${ }^{a}$ Other sources of poisoning include using the contaminated water and the sources we cannot identify

foodborne disease outbreaks were bacteria and poisonous plants in Guangxi.

During the five-year reporting period, the number of foodborne disease outbreaks, cases and deaths decreased compared with the period from 2005 to 2009 in Guangxi [10]. This suggests that the enhanced surveillance of food poisoning had an effect on food safety since the new law was established in 2009. The new law was focused on strengthening food safety risk monitoring and assessment, and punishment for violations was more stringent than before. From 2010 to 2016, the number of foodborne disease outbreaks reported annually fluctuated substantially, and the number of outbreaks in 2014 to 2016 was higher than that in 2012 and 2013. This might be due to the reformation of the Guangxi Supervision and Management System for Food and Drugs in October 2013, which brought about a change in supervision staff and departments of catering services.

Our result was in line with previous studies, which showed that foodborne disease outbreaks were likely to occur in warm months $[4,11,12]$. Foodborne disease outbreaks were related to changes in weather [13]. The natural environment in Guangxi is subtropical monsoon weather, and this warm and humid weather is conducive to bacteria and herbal medicine growth, which is medicine made from plants and used to prevent or treat disease or promote health. Therefore, some special

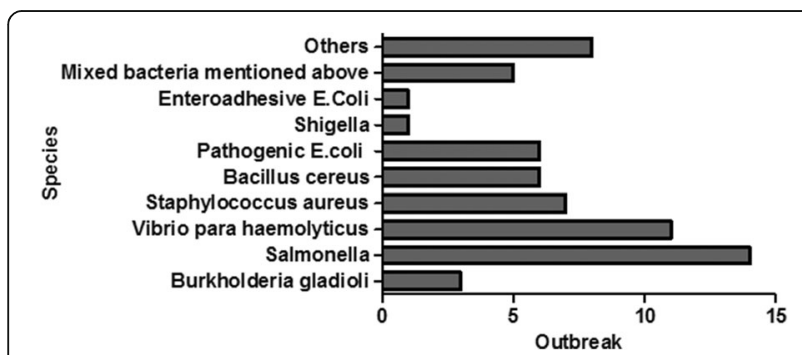

Fig. 1 Number of outbreaks of the bacterial causative hazard, Guangxi, South China, 2010-2016 measures, such as strengthening public awareness and supervision of food safety, are needed to prevent foodborne disease outbreaks in these months in which foodborne disease outbreaks occurred frequently.

Li [14] found that most deaths from foodborne disease outbreaks took place in private homes between 2002 and 2011 in China. In accordance with this current study, private homes were the most severely afflicted foodborne disease outbreaks, where $78.26 \%$ of deaths occurred. This finding shows that it is extremely important for the public health authorities to teach the public population how to save themselves in case poisoning occurs at home. In addition, we also found that approximately three-quarters of outbreaks occurred in rural areas and towns, especially at schools in remote areas. Good environmental hygiene can help us to prevent many illnesses caused by infection from noxious pathogens, and can prevent noxious pathogens contaminating food. Therefore, if supervision of environmental hygiene is improved, poisoning may be controlled.

Improper practices of food handlers in hand, equipment and utensil hygiene; maintenance of temperature of food ready for consumption; cooking temperature; and thawing relates directly to foodborne disease and are the main cause of foodborne disease outbreaks [15-17]. In this study of 138 foodborne disease outbreaks, improper

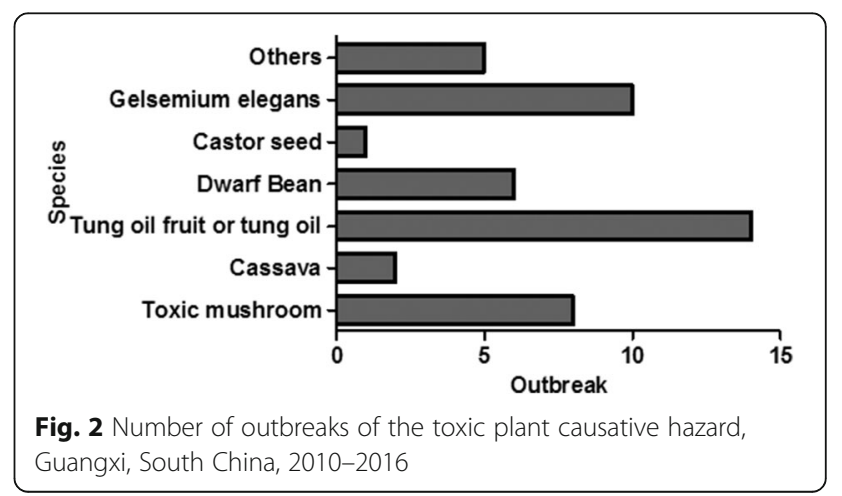


Table 6 Number of cases and deaths by different Causative hazard, Guangxi, South China, 2010-2016

\begin{tabular}{|c|c|c|}
\hline Causative hazard & $\begin{array}{l}\text { No.(\%) of } \\
\text { cases }\end{array}$ & $\begin{array}{l}\text { No.(\%) of } \\
\text { deaths }\end{array}$ \\
\hline Bacteria & $2123(63.41)$ & $6(13.04)$ \\
\hline Burkholderia gladioli & $11(0.33)$ & $6(13.04)$ \\
\hline Salmonella & $735(21.95)$ & $0(0.00)$ \\
\hline Vibrio para haemolyticus & $375(11.20)$ & $0(0.00)$ \\
\hline Staphylococcus aureus & $128(3.82)$ & $0(0.00)$ \\
\hline Bacillus cereus & $113(3.38)$ & $0(0.00)$ \\
\hline Pathogenic E.coli & $108(3.23)$ & $0(0.00)$ \\
\hline Shigella & $81(2.42)$ & $0(0.00)$ \\
\hline Enteroadhesive E.Coli & $25(0.75)$ & $0(0.00)$ \\
\hline Mixed bacteria mentioned above & $284(8.48)$ & $0(0.00)$ \\
\hline Others & $263(7.86)$ & $0(0.00)$ \\
\hline Chemical agents & $131(3.91)$ & $8(17.39)$ \\
\hline Fluoroacetamide & $2(0.06)$ & $2(4.35)$ \\
\hline Tetramine & $7(0.21)$ & $2(4.35)$ \\
\hline $\begin{array}{l}\text { Sulfur dioxide and dehydroacetic } \\
\text { acid }\end{array}$ & $83(2.48)$ & $0(0.00)$ \\
\hline Nitrite & $18(0.54)$ & $0(0.00)$ \\
\hline Others & $21(0.63)$ & $4(8.70)$ \\
\hline Toxic insects/food products & $15(0.45)$ & $3(6.52)$ \\
\hline Toxic honey & $11(0.33)$ & $2(4.35)$ \\
\hline Mylabris cichorii & $4(0.12)$ & $1(2.17)$ \\
\hline Poisonous plants & $711(21.24)$ & $26(56.52)$ \\
\hline Toxic mushroom & $52(1.55)$ & $5(10.87)$ \\
\hline Cassava & $8(0.24)$ & $2(4.35)$ \\
\hline Tung oil fruit or tung oil & $315(9.41)$ & $0(0.00)$ \\
\hline Dwarf bean & $136(4.06)$ & $0(0.00)$ \\
\hline Castor seed & $21(0.63)$ & $0(0.00)$ \\
\hline Gelsemium elegans & $112(3.35)$ & $17(36.96)$ \\
\hline Others & $67(2.00)$ & $2(4.35)$ \\
\hline Factors unconfirmed & $368(10.99)$ & $3(6.52)$ \\
\hline
\end{tabular}

Abbreviation: E.coli Escherichia coli

cooking and cross contamination were the main causes during meal preparation. Moreover, the lack of ability to identify poisonous food can easily cause poisoning, and we found that ingesting poisonous food by mistake was the primary route of contracting foodborne disease outbreaks in Guangxi. Therefore, enhancing food safety knowledge and hygiene practices of handlers and improving the knowledge of residents about toxic food may be key points for ongoing supervision.

Bacterial food poisoning is a prevalent foodborne disease worldwide $[18,19]$. WHO showed that the pathogens resulting in the most foodborne cases were norovirus, Campylobacter spp., enterotoxigenic e.coli, diarrheal disease due to non-typhoidal S. enterica, and
Shigella spp. [20]. In their study found that norovirus, enteropathogenic e.coli, V. cholerae, and Shigella spp. were responsible for large numbers of deaths among the diarrheal diseases and Salmonella Typhi, hepatitis A virus, invasive infections due to non-typhoidal S. enterica and Salmonella Paratyphi A were responsible for the most deaths among the extra-intestinal enteric diseases. In this study, which focused only on outbreaks of foodborne disease of toxic nature (vs. infectious), we found that Salmonella, Vibrio para haemolyticus, Staphylococcus aureus, chemical agents, and tung oil fruit or tung oil were responsible for most cases. In addition, poisonous plants were the leading cause of death. We did not detect Campylobacter in all the samples. As is known, the relative frequency of foodborne disease depends strongly on geography, local diet, sanitary conditions and general public health, among many other factors. The main reason for the differences in foodborne hazards between WHO and our study may be a response to the local diet. In China, dairy foods, the main vehicles for Campylobacter, accounted less but frequently in United States [21]. In China, people generally believe that wild-harvested products, including mushrooms, have high nutritional and medicinal values and the risky behavior of collecting and consuming wild plants (such as poisonous mushroom, Gelsemium elegans and tung oil fruit) happens mostly in remote districts in household clusters [22]. Therefore, increasing public awareness about food safety of poisonous plants is an important elements of preventing and controlling future foodborne disease outbreak.

Our study showed that public awareness about food safety of poisonous plant, hand hygiene of handlers and policies about the interventions on foodborne illness were important elements preventing and controlling foodborne disease. Our findings might help in the development of a better foodborne disease monitoring system based on the characteristics of Guangxi. From this, we can list high-risk foods, including meat, poultry and poisonous plants (e.g. tung oil, tung oil fruit and Gelsemium elegans), to put forward appropriate measures for prevention and control. Tung oil is rich in eleostearic acid. If eaten by mistake, symptoms of poisoning, such as nausea, vomiting, abdominal pain, breathing difficulties, limb twitches, coma and laryngeal muscle spasm, appear within $2 \mathrm{~h}$. Gelsemium elegans contains a variety of alkaloids, such as gelsemine free base, which can inhibit the respiratory center and may eventually cause respiratory center paralysis and death due to respiratory failure. Improving the training and food safety awareness of food handlers, enhancing the systems of food procurement and inspection, strengthening the disinfection of tableware and preventing improper handling and cross contamination during food preparation should also 
be included. Moreover, skills of investigators, such as their ability to investigate foodborne disease, identify poisonous food, and their awareness about food safety should be enhanced.

Several limitations are necessary to be noted in the current study. First, we only discussed the epidemic of foodborne disease outbreaks of Guangxi, a province of China. Guangxi is one of five ethnic minority autonomous regions in China, which includes twelve minorities and 46.82 million people in 2012. It is the only coastal autonomous region which is adjacent to the land and sea of Vietnam and the permanent venue of ChinaASEAN Expo. Thus, we think it is necessary for us to discuss the epidemic characteristics of foodborne disease outbreaks and the security status of food in this autonomous region. Second, $13.04 \%$ of outbreaks were found without a confirmed etiologic agent in our study. We have made efforts to improve the collection of suspicious food after foodborne disease outbreaks occurring and the ability of food detection of our laboratory. Third, since some cases (e.g. mild acute gastro-enteritis) are self-curable and hardly recognized, reported or investigated, it is susceptible to reporting bias. Fourth, the detection ability of the present clinical laboratories in Guangxi is relatively limited, and some pathogens are perhaps not identified routinely. Finally, these findings might not be generalizable to other areas in China.

\section{Conclusion}

The primary causative hazard of foodborne disease outbreaks in Guangxi were bacteria and poisonous plants, and the contributing factors were ingesting poisonous food by mistake, improper cooking and cross contamination. Therefore, improving the detection of bacteria in food, and the market supervision of poisonous plants and propaganda knowledge about food safety might be helpful for us to control foodborne disease outbreaks.

\section{Additional file}

Additional file 1: Table Number of outbreaks, cases and deaths by month, Guangxi, South China, 2010-2016. (DOC 42 kb)

\section{Abbreviations \\ CDC: Centers for Disease Control; CFDA: China Food and Drug Administration: DALYs: Disability-adjusted life years; FERG: Foodborne Disease Burden Epidemiology Reference Group; WHO: World Health Organization}

\section{Acknowledgements}

We are extremely grateful to all the participants in our study and sincerely thank Guangxi Food and Drug Administration,Guangxi Medical University, Guangxi Centre for Disease Prevention and Control, Huazhong University of Science and Technology and Guangxi Zhuang Autonomous Region Health and Family Planning Commission.

\section{Funding}

This study was funded by the Guangxi Food and Drug Safety Project (GFD-201520), but played no role in the design of the study, analysis and interpretation of data or in the writing of the manuscript.

\section{Availability of data and materials}

The data that support the findings of this study are available from the Public Health Emergency Report and Management Information System of the China Information System for Disease Control and Prevention, and these data are not publicly available.

\section{Authors' contributions}

XBY and YQL conceived the study and led the study design. XBY, YQL, YLH, $J J Y, Z H L, Y N L, X T Y, Z H, J J L$ and ZHM collected and performed the statistical analysis together. BW, ZZT, SDC, DCL and SFN made substantial contributions to the data analysis and interpretation. XBY, YQL and YLH wrote the manuscript. All the authors contributed to the interpretation of the data, critical revision of the manuscript and read and approved the final manuscript.

\section{Ethics approval and consent to participate}

All procedures performed in studies did not involve human participants and animals. The data used for our study were openly available in Public Health Emergency Report and Management Information System of the China Information System for Disease Control and Prevention and we received permission to use of this information in this paper from the office of Food Safety Commission.

\section{Competing interests}

The authors declare that they have no competing interests.

\section{Publisher's Note}

Springer Nature remains neutral with regard to jurisdictional claims in published maps and institutional affiliations.

\section{Author details}

1Department of Epidemiology and Health Statistics, School of Public Health of Huazhong University of Science and Technology, Wuhan, Hubei, China. ${ }^{2}$ Guangxi Food and Drug Administration, Nanning, Guangxi, China.

${ }^{3}$ Department of Epidemiology and Health Statistics, School of Public Health of Guangxi Medical University, Nanning, Guangxi, China. ${ }^{4}$ Center for Genomic and Personalized Medicine, Guangxi Medical University, Nanning, Guangxi,

China. ${ }^{5}$ Guangxi Collaborative Innovation Center for Genomic and Personalized Medicine, Nanning, Guangxi, China. ${ }^{6}$ Department of Occupational Health and Environmental Health, School of Public Health of Guangxi Medical University, Shuangyong road, Nanning 530021, Guangxi,

China. ${ }^{7}$ Guangxi Zhuang Autonomous Region Center for Disease Control and Prevention, Nanning, Guangxi, China. ${ }^{8}$ School of Information and Management of Guangxi Medical University, Nanning, Guangxi, China. ${ }^{9}$ Guangxi Zhuang Autonomous Region Health and Family Planning Commission, Nanning, Guangxi, China.

Received: 12 April 2017 Accepted: 10 April 2018

Published online: 18 April 2018

\section{References}

1. Food safety at risk in Asia and the Pacific. http://www.fao.org/Newsroom/ en/news/2004/43073/index.html. Accessed 24 May 2004.

2. Organization WH. WHO estimates of the global burden of foodborne diseases: foodborne diseases burden epidemiology reference group 2007-2015. 2015.

3. Furness BW, Simon PA, Wold CM, Asarian-Anderson J. Prevalence and predictors of food insecurity among low-income households in Los Angeles County. Public Health Nutr. 2004;7(6):791-4

4. Jun FX, Ju ZZ. Analysis of foodborne disease outbreaks in China from 2001 to 2010. Chin Agric Sci Bull. 2012;28(27):4.

5. Haibo L, Laiying H, Weijie Y, Yangjian C, Chunmei C, Jun W. Analysis of the food poisoning in China from 2004 to 2013. Chin J Food Hygiene. 2015; 27(1):45-9.

6. Lam HM, Remais J, Fung MC, Xu L, Sun SS. Food supply and food safety issues in China. Lancet. 2013;381(9882):2044-53. 
7. Yan X, Wang B, Tao X, Hu Q, Cui Z, Zhang J, Lin Y, You Y, Shi X, Grundmann H. Characterization of Staphylococcus aureus strains associated with food poisoning in Shenzhen, China. Appl Environ Microbiol. 2012;78(18):6637-42.

8. Deng WQ, Li TH, Xi PG, Gan LX, Xiao ZD, Jiang ZD. Peptide toxin components of amanita exitialis basidiocarps. Mycologia. 2011;103(5):946-9.

9. Organization WH. Foodborne disease outbreaks : guidelines for investigation and control. 2008.

10. Huang Z, Tang Z, Chen X. Analysis on epidemiological characteristics of food poisoning events in Guangxi from 2000 to 2011. Pract Prev Med. 2012;19:4.

11. Xiu ML, Yan C, Yun CG, Zhu TW. Foodborne diseases outbreaks in 2005report of National Foodborne Diseases Surveillance Network in China. Chin J Food Hygiene. 2008;20(6):4.

12. Olea A, Diaz J, Fuentes R, Vaquero A, Garcia M. Foodborne disease outbreaks surveillance in Chile. Rev Chil Infectol. 2012;29(5):504-10.

13. Bentham G, Langford IH. Climate change and the incidence of food poisoning in England and Wales. Int J Biometeorol. 1995;39(2):81-6.

14. Ting TL. Analysis of the food poisoning in China from 2002 to 2011. J Shanxi Med Univ. 2012;43(6):4.

15. Lima GC, Loiko MR, Casarin LS, Tondo EC. Assessing the epidemiological data of Staphylococcus aureus food poisoning occurred in the state of Rio Grande do Sul, southern Brazil. Braz J Microbiol. 2013:44(3):759-63.

16. Strategic plan for food safety including foodborne zoonoses 2013-2022. http://www.who.int/foodsafety/strategic-plan/en/. Accessed 2013.

17. Greig JD, Todd EC, Bartleson CA, Michaels BS. Outbreaks where food workers have been implicated in the spread of foodborne disease. Part 1. Description of the problem, methods, and agents involved. J Food Prot. 2007;70(7):1752-61.

18. Nguyen VD, Bennett SD, Mungai E, Gieraltowski L, Hise K, Gould LH. Increase in multistate foodborne disease outbreaks-United States, 1973-2010. Foodborne Pathog Dis. 2015;12(11):867-72.

19. Tewari A, Abdullah S. Bacillus cereus food poisoning: international and Indian perspective. J Food Sci Technol. 2015;52(5):2500-11.

20. Kirk MD, Pires SM, Black RE, Caipo M, Crump JA, Devleesschauwer B, Dopfer D, Fazil A, Fischer-Walker CL, Hald T, et al. World Health Organization estimates of the global and regional disease burden of 22 foodborne bacterial, protozoal, and viral diseases, 2010: a data synthesis. PLoS Med. 2015;12(12):e1001921.

21. Surveillance for Foodborne Disease Outbreaks, United States, 2015 Annual Report. https://www.cdc.gov/foodsafety/pdfs/2015FoodBorneOutbreaks_ 508.pdf. Accessed 2015.

22. Liu J, Bai L, Li W, Han H, Fu P, Ma X, Bi Z, Yang X, Zhang X, Zhen S, et al. Trends of foodborne diseases in China: lessons from laboratory-based surveillance since 2011. Front Med. 2017;12(1):48-57.

\section{Ready to submit your research? Choose BMC and benefit from:}

- fast, convenient online submission

- thorough peer review by experienced researchers in your field

- rapid publication on acceptance

- support for research data, including large and complex data types

- gold Open Access which fosters wider collaboration and increased citations - maximum visibility for your research: over $100 \mathrm{M}$ website views per year

At BMC, research is always in progress.

Learn more biomedcentral.com/submissions 